\title{
Effect of the Gamma Knife Treatment on the Trigeminal Nerve Root in Chinese Patients with Primary Trigeminal Neuralgia
}

\author{
Primer Trigeminal Nerraljili Çinli Hastalarda Trigeminal Sinir Kökü \\ Üzerine Gamma Bıçă̆ı Tedavisinin Etkisi
}

\author{
Zhi-Xiu SONG ${ }^{1}$, Wei QIAN ${ }^{2}$, Yu-Quan WU², Fang-Jie SUN ${ }^{3}$, Jun FEI ${ }^{2}$, Run-Sheng HUANG ${ }^{2}$, Jing-Yu FANG ${ }^{2}$, \\ Cai-Zhen WU², You-Ming AN², Daxin Wang ${ }^{4}$, Jun YANG ${ }^{3,4}$ \\ ${ }^{1}$ The First Affiliated Hospital of Xinxiang Medical University, Weihui, China \\ 2117 Hospital of People's Liberation Army, Center of Gamma Knife, Hangzhou, China \\ ${ }^{3}$ Xinxiang Institute for New Medicine, Xinxianag, China \\ 4Jiangsu Su Bei People's Hospital, Yangzhou, China
}

Corresponding Author: Jun YANG / E-mail: bcd2009@126.com

\begin{abstract}
AIM: To understand the mechanism of the gamma knife treating the trigeminal neuralgia.

MATERIAL and METHODS: Using the MASEP-SRRS type gamma knife treatment system, 140 Chinese patients with trigeminal neuralgia (NT) were treated in our hospital from 2002 to 2010 , in which the pain relief rate reached $95 \%$ and recurrence rate was $3 \%$ only. We investigated the effect of the gamma knife treatment on the trigeminal nerve root in 20 Chinese patients with primary trigeminal neuralgia by the magnetic resonance imager (MRI) observation.

RESULTS: 1) The cross-sectional area of trigeminal nerve root became smaller and MRI signals were lower in the treatment side than those in the non-treatment side after the gamma knife treatment of primary trigeminal neuralgia; 2 ) in the treatment side, the cross-sectional area of the trigeminal nerve root decreased significantly after the gamma knife treatment; 3 ) there was good correlation between the clinical improvement and the MRI findings; and 4) the straight distance between the trigeminal nerve root and the brainstem did not change after the gamma knife treatment.
\end{abstract}

CONCLUSION: The pain relief induced the gamma knife radiosurgery might be related with the atrophy of the trigeminal nerve root in Chinese patients with primary trigeminal neuralgia.

KEYWORDS: Gamma knife, Trigeminal nerve root, Primary trigeminal neuralgia, MRI

öz

AMAÇ: Trigeminal nevralji tedavisinde gamma bıçağı mekanizmasının anlaşılması.

YÖNTEM ve GEREÇLER: MASEP-SRRS tipi gamma bıçağı tedavi sistemi kullanılarak hastanemizde trigeminal nevraljili 140 Çinli hasta 2002 ve 2010 yılları arasında tedavi edildi ve ağrının geçmesi oranı $\% 95$ 'e ulaşıp tekrarlama oranı sadece $\% 3$ oldu. Gamma bıçağı tedavisinin trigeminal sinir kökü üzerine etkisini primer trigeminal nevraljili 20 Çinli hastada manyetik rezonans görüntüleyici (MRG) gözlemiyle inceledik.

BULGULAR: 1) Trigeminal sinir kökünün çapraz kesit alanı primer trigeminal nevraljinin gamma bıçăı tedavisinden sonra tedavi tarafında tedavi edilmemiş tarafa göre daha küçük ve MRG sinyalleri daha düşüktü; 2) tedavi tarafında trigeminal sinir kökünün çapraz kesit alanı gamma bıçağı tedavisinden sonra önemli ölçüde azaldı; 3) klinik iyileşme ve MRG bulguları arasında iyi korelasyon vardı; ve 4) trigeminal sinir kökü ile beyin kökü arasındaki düz mesafe gamma bıçağı tedavisi sonrasında değişmedi.

SONUÇ: Gamma bıçağı radyocerrahisinin oluşturduğu ağrı giderme primer trigeminal nevraljili Çinli hastalarda trigeminal sinir kökünün atrofisiyle ilişkili olabilir.

ANAHTAR SÖZCÜKLER: Gamma bıçağı, Trigeminal sinir kökü, Primer trigeminal nevralji, MRG

\section{INTRODUCTION}

Trigeminal neuralgia (TN) is a neuropathic disorder characterized by episodes of intense pain in the face, originating from the trigeminal nerve (2). The disorder is typically characterized by episodes of intense facial pain that last from a few seconds to several minutes or hours and may occur paroxysmally. Individual attacks usually affect one side of the face at a time, which $10-12 \%$ of cases are bilateral, or occurring on both sides (3).

It was once believed that the nerve was compressed in the opening from the inside to the outside of the skull (1); but newer leading research indicates that it is an enlarged blood 
vessel - possibly the superior cerebellar artery - compressing or throbbing against the microvasculature of the trigeminal nerve near its connection with the pons. Such a compression can injure the nerve's protective myelin sheath and cause erratic and hyperactive functioning of the nerve. This can lead to pain attacks at the slightest stimulation of any area served by the nerve as well as hinder the nerve's ability to shut off the pain signals after the stimulation ends (12).

It is only recommended for surgical therapy if the medical treatment is not effective (13). While there may be pain relief there is also frequently numbness post procedure (15). Microvascular decompression appears to result in the longest pain relief (15). Percutaneous radiofrequency thermorhizotomy may also be effective (14) as may stereotactic radiosurgery but the effectiveness decreases with time (5). Few studies have reported how the stereotactic radiosurgery influences the trigeminal nerve root in Chinese patients with trigeminal neuralgia. Using MASEP-SRRS type stereotactic radiosurgery system, 140 Chinese patients with trigeminal neuralgia (NT) were treated in our hospital from March 2002 to March 2010, in which the pain-relief rate reached $95 \%$ and recurrence rate was $3 \%$ only. For understanding the mechanism of the gamma knife treating the trigeminal neuralgia, we investigated the effect of the gamma knife treatment on the trigeminal nerve root in 20 Chinese patients with primary trigeminal neuralgia, whose only one side was attacked and the facial pain was relieved for over one year, by the magnetic resonance imager (MRI) observation.

\section{MATERIAL and METHODS}

\section{Patients}

Twenty Chinese patients diagnosed with primary trigeminal neuralgia including 7 male and 13 female, 36-80 years old (average 62.0 \pm 6.8 years old) and 1-10 years (average 4.8 \pm 2.1 years) disease history, were treated in our hospital from March 2002 to March 2010. Twelve cases were attacked in the right side and 8 cases in the left side. The typical symptoms of the primary trigeminal neuralgia were as follows: 1) unilateral pain; 2) lancination or stabbing pain; 3) pain with recurrent paroxysms of sharp, maxillary and mandible distribution with the trigeminal nerve; and 4) attacks occurred as often as multiple times daily or were rare during sleep. The triggers included brushing teeth, washing face, eating and talking, cold exposure, chewing and so on.

\section{Inclusion Criteria}

Inclusion criteria were as follows: (a) agreement to sign the informed consent form; (b) eligibility was checked before the experiments (exclusion criteria: pregnancy, tumor, cardiovascular, gastrointestinal, respiratory, brain, kidney, endocrine or other diseases, smoking, intake of drugs, radio frequency treatment, glycerol injection and craniotomy surgery); (c) participants were asked not to drink any alcohol, caffeine containing beverages and analgesic medication during the experiment; (d) over 18 years old. All experiments were approved by our hospital Ethics Committees and carried out according to the Declaration of Helsinki.

\section{Gamma Knife Treatment}

Under the local anesthesia, brain MRI was checked in all cases after setting Leksell collimating apparatus head frame (Leksell Gamma Knife frame, Lekta, Sweden). In order to observe the sheath inflammation of trigeminal nerve more clearly, MRI 3D-FISP sequence thin layer scanning and gamma knife control system input image information were used. Determine the trigeminal nerve root near the brain stem as the therapeutic target by TPS software program, and choose $4 \mathrm{~mm}$ collimator and conduct dual target irradiation for isocenter (range 80.0$90.0 \mathrm{~Gy}$ ), which $50 \%$ isodose line was tangent with the brain stem edge. The period of the gamma knife treatment was 1320 months (average of 14.0 \pm 3.8 months).

\section{MRI Examination}

GE Signal Excite 1.5T Superconducting MRI and 3D-FSPGR Sequence scanning were employed to show the trigeminal nerve root structures and the brain stem. The thin layer scanning focused on the pones by forming three-dimensional steady precession fast imaging (3D-TOF-FISP) and sequence [TR $12 \mathrm{~ms}$, TE $4.5 \mathrm{~ms}$, thickness $2.0 \mathrm{~mm}$, layer distance-1 mm, matrix $256 \times 256$, field of vision (FOV) $240 \times 240$ ]. It ranged from pontomedullary sulcus to the middle of pones. According to the original image of trigeminal nerve root entry zone (REZ) and preganglionic segment (PGS) from 3D-TOF, the coronal cross-sectional area of the trigeminal nerve roots and the points between two locations were measured.

\section{Statistical Analysis}

Data were expressed as mean \pm standard error of the mean (S.E.M.) and performed with the SPSS 17.0 statistical package, with two-way analysis of variance (ANOVA) followed by the Bonferroni test. Significance was accepted at $P<0.05$.

\section{RESULTS}

\section{Effect of the Gamma Knife Treatment on Primary Trigeminal Neuralgia}

The gamma knife treatment could induce the pain-relief in Chinese patients with primary trigeminal neuralgia. In the patients who were treated with the Gamma knife, the curative effect in all 20 Chinese patients of primary trigeminal neuralgia was the pain-relief 10 cases $(50.0 \%)$ and the facial numbness 15 cases (75.0\%) 6 months after the gamma knife treatment; the curative effect was the pain-relief 19 cases (95.0\%) and the facial numbness 3 cases (15.0\%) 12 months after the treatment; the curative effect was the pain-relief 17 cases $(85.0 \%)$ and the facial numbness 5 cases $(25.0 \%) 24$ months after the treatment; and the curative effect was the pain-relief 15 cases (75.0\%) and the facial numbness 8 cases (40.0\%) 36 months after the treatment (Figure 1). 


\section{Change of the Trigeminal Nerve Root After the Gamma Knife Treatment}

The patients were MRI inspected before the treatment, 6,12 , 24 and 36 months after the treatment. The cross-sectional area of the trigeminal nerve root became smaller after the

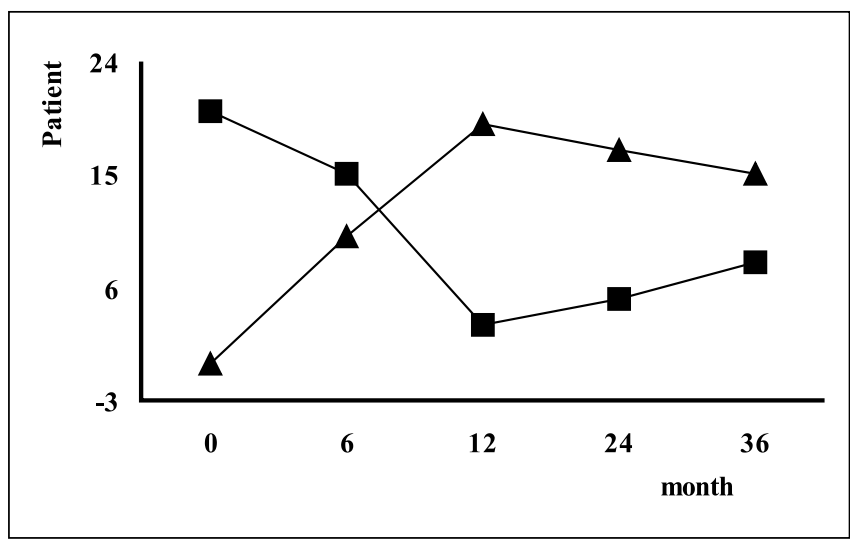

Figure 1: Effect of the gamma knife treatment on primary trigeminal neuralgia. $\boldsymbol{\Delta}$ indicates the number of the patients of pain-relief; $\mathbf{a}$ indicates the number of the patients of facial numbness. gamma knife treatment in Chinese patients with primary trigeminal neuralgia. Comparing with the MRI finding before the treatment, the trigeminal nerve roots became smaller significantly in 12 patients $(60.0 \%) 6$ months after the treatment, 17 patients (85.0\%) 12 months after the treatment, 18 patients (90.0\%) 24 months after the treatment and 19 patients (95.0\%) 36 months after the treatment.

All of the MRI images showed the structures of the trigeminal nerve root were good both before and after the gamma knife treatment (Figure 2). The cross-sectional area of trigeminal nerve root and MRI signals between the treatment side and non-treatment side showed different before the gamma knife treatment of the trigeminal neuralgia (Figure 3). The crosssectional area of trigeminal nerve root became smaller and MRI signals showed lower in the treatment side than those in the non-treatment side (Figure 4,5). Compared with that before the gamma knife treatment, the cross-sectional area of the trigeminal nerve root decreased significantly from $5.74 \pm 0.4 \mathrm{~mm}^{2}$ to $3.52 \pm 0.8 \mathrm{~mm}^{2}$ after the gamma knife treatment in the treatment side $(P<0.01)$; but in the nontreatment side, the cross-sectional area of the trigeminal nerve root did not change after the gamma knife treatment $\left(5.56 \pm 0.3 \mathrm{~mm}^{2}\right.$ vs. $\left.5.44 \pm 0.5 \mathrm{~mm}^{2}, P>0.05\right)$ (Figure 6).
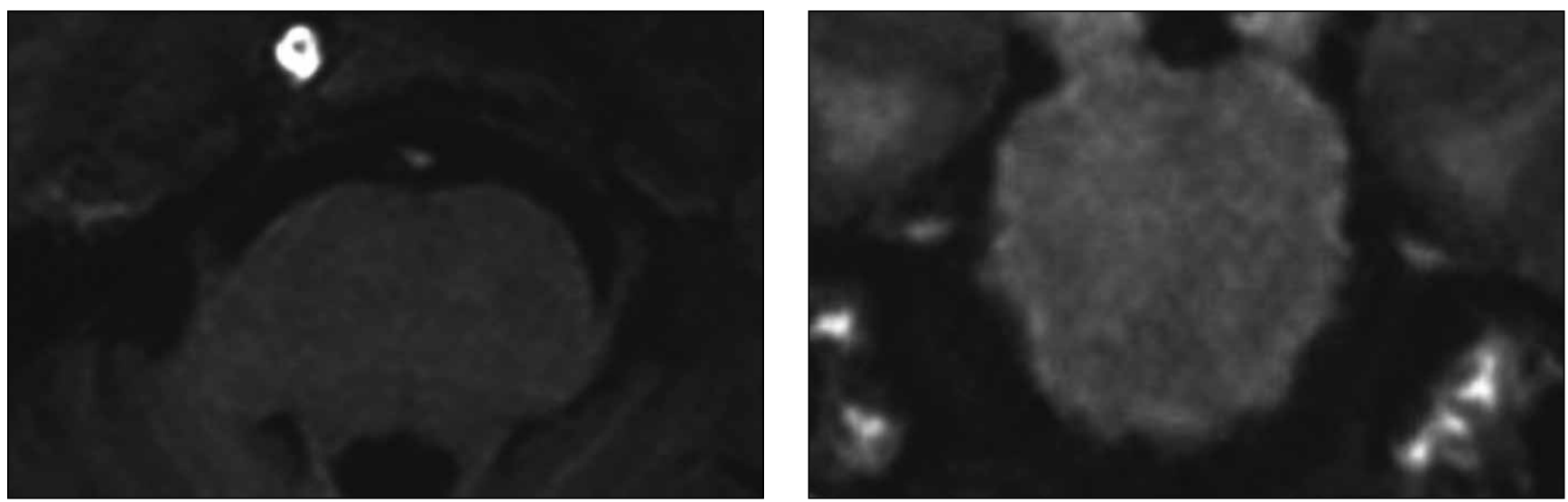

Figure 2: The MRI screenage of the trigeminal nerve roots before the gamma knife treatment.
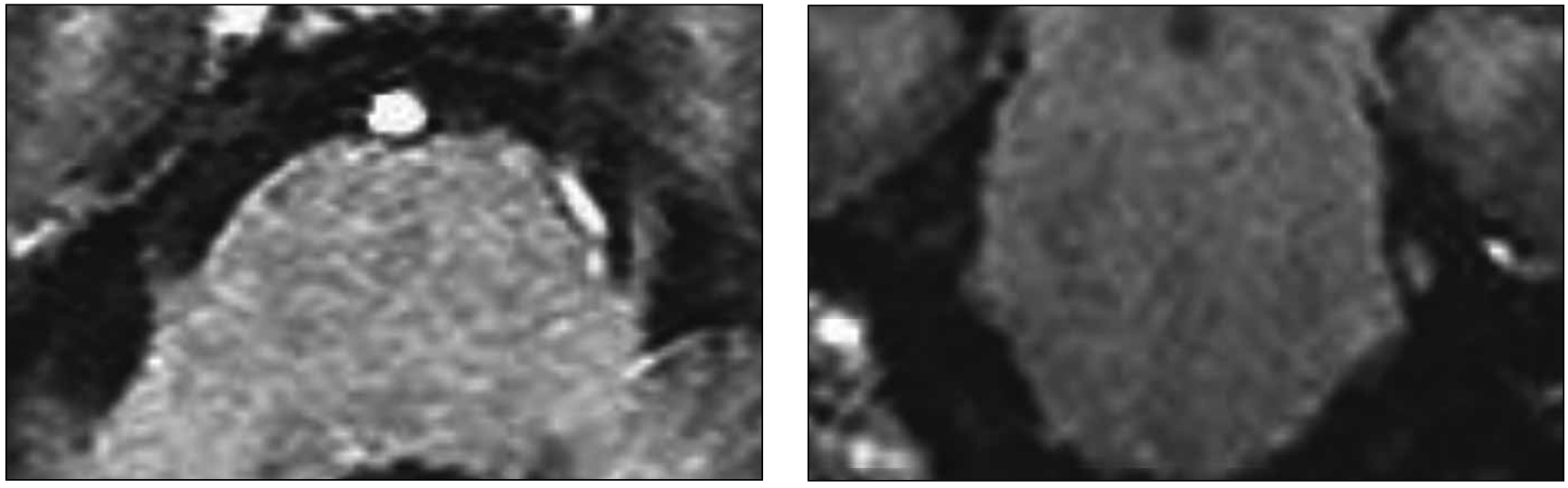

Figure 3: The MRI screenage of the trigeminal nerve roots after the gamma knife treatment. 


\section{The Correlation Between the Clinical Improvement and the MRI Findings}

There was good correlation between the clinical improvement (pain relief and facial numbness recurrence) and the MRI findings (cross-sectional area of the trigeminal nerve and MRI signal), i.e., the smaller the cross-sectional area of the trigeminal nerve, the lower the MRI signal, the more the pain relief, and the less the facial numbness recurrence (Table I).

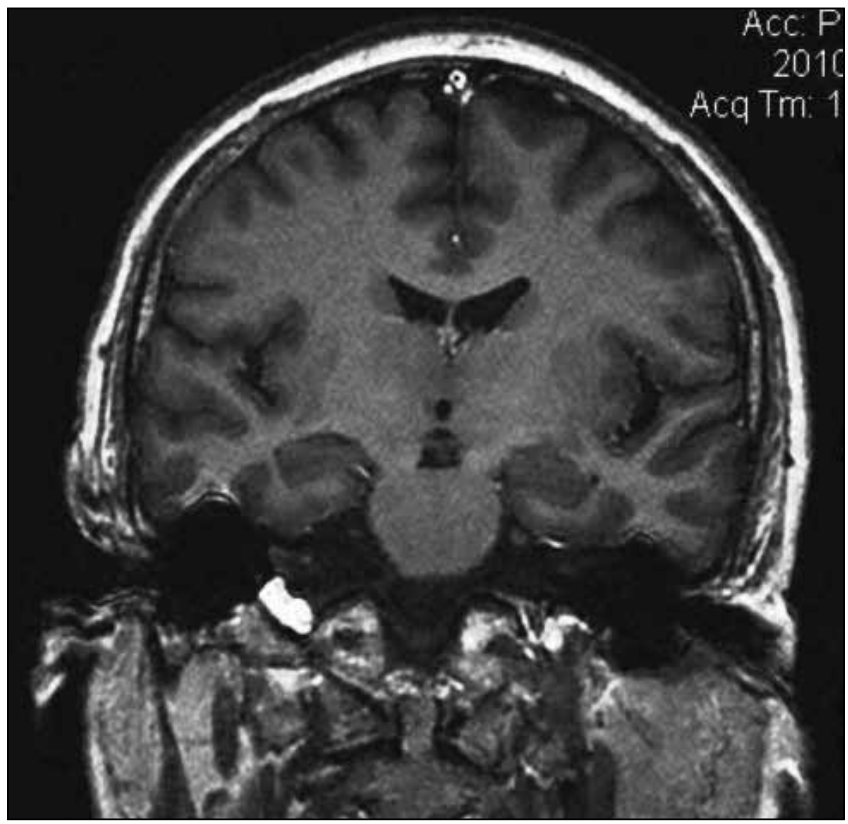

\section{Change of the Straight Distance Between the Trigeminal Nerve Root and Brainstem}

Compared with that before the gamma knife treatment, the straight distance between the trigeminal nerve root and the brainstem did not change $(30.6 \pm 2.5 \mathrm{~mm}$ vs. $9.4 \pm 2.3 \mathrm{~mm}$, $p>0.05$ ) (Figure 7).

Figure 4: The MRI image of the right trigeminal nerve root 18 months after the gamma knife treatment.
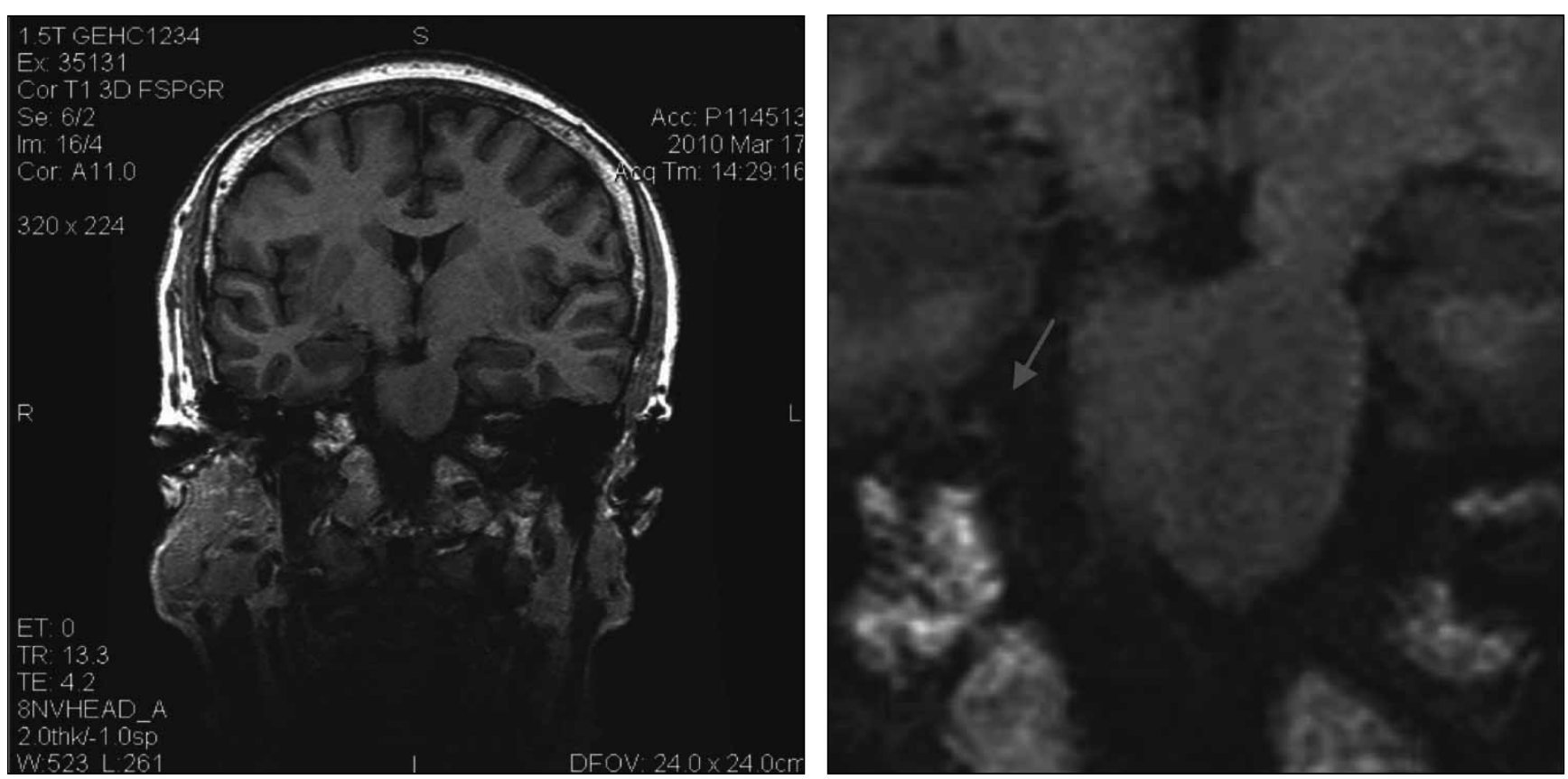

Figure 5: The MRI image of the right trigeminal nerve root 24 months after the gamma knife treatment. 


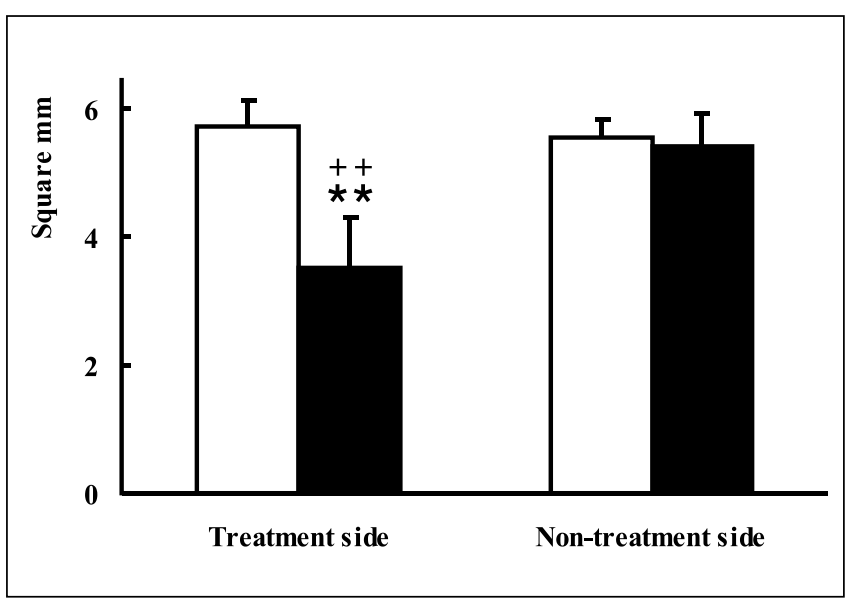

Figure 6: Effect of the gamma knife treatment on the crosssectional area of the trigeminal nerve root. $\square$ indicates the cross-sectional area of the trigeminal nerve root before the gamma knife treatment. $\mathbf{a}$ indicates the cross-sectional area of the trigeminal nerve root after the gamma knife treatment. The data are expressed as mean \pm SEM. The number of each group is 20. ${ }^{* *} p<0.01$ is used for the cross-sectional area comparison of the trigeminal nerve root before and after the gamma knife treatment; ${ }^{++} p<0.01$ is used for the cross-sectional area comparison of the trigeminal nerve root in the treatment side and in non- treatment side.

\section{DISCUSSION}

It has been taking advantage in the pain relief for the stereotactic radiosurgery to treat primary trigeminal neuralgia, which has high efficacy rate (88-96\%), good quality life rate (about $85 \%$ ) and low complication and recurrence rate $(4-12 \%)(10,17)$. Compared with the classic vascular decompression of the trigeminal nerve, it was satisfied from less complication, efficiency rate and patients' satisfaction $(7,11)$. It has been regarding as the first choice for patients in line with indication $(4,6)$. The cause of primary trigeminal neuralgia was considered concerned with some local factors currently, such as vascular compression, inflammation, arachnoids adhesions, and the end cranium hyperplasia and viral infection (8). The present study also showed that the curative effect rate of pain-relief was very high and the facial numbness recurrence rate was very low in all 20 Chinese patients with primary trigeminal neuralgia after the gamma knife treatment.

For the stereotactic radiosurgery treating primary trigeminal neuralgia, the target doses of 60 and 70 Gy had very little impact on the structure of the trigeminal nerve; irradiation at $80 \mathrm{~Gy}$ could cause partial degeneration and loss of axons and demyelization; and a 100-Gy dose can cause some necrosis of neurons (16). Using an effective MRI inspection in 89 patients, 82 patients could be seen vascular compression, which mainly occurred by the superior cerebella artery with the percentage of $78 \%$ (9). The present data showed that the cross-sectional area of the trigeminal nerve root significant atrophy in corona view with an average decline of $39.8 \% 12$

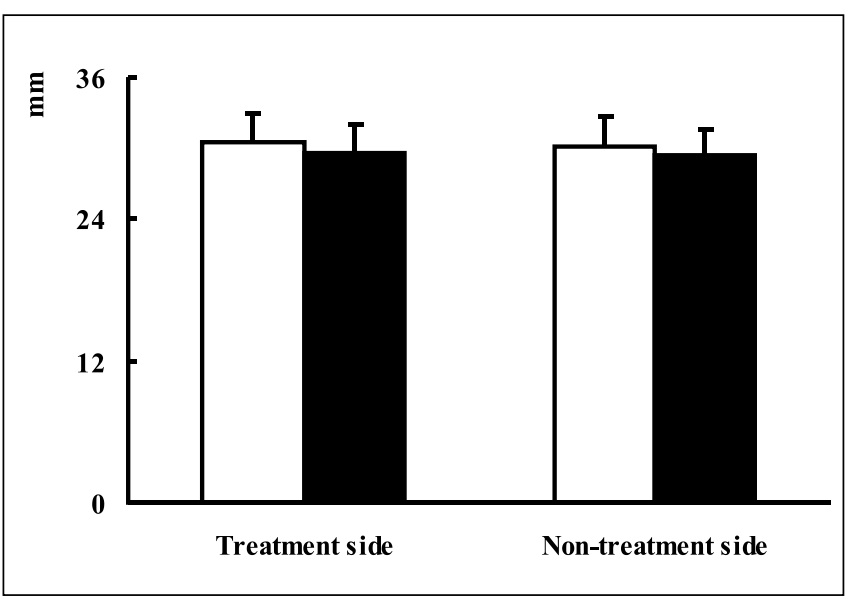

Figure 7: Effect of the gamma knife treatment on the straight distance between the trigeminal nerve root and the brainstem. $\square$ indicates the straight distance between the trigeminal nerve root and the brainstem before the gamma knife treatment. indicates the straight distance between the trigeminal nerve root and the brainstem after the gamma knife treatment. The data are expressed as mean \pm SEM. The number of each group is 20 .

months after the gamma knife treatment in Chinese patients with primary trigeminal neuralgia, i.e. the trigeminal nerve trunk in the treatment side showed lower signal change after the treatment than that before the treatment; and the straight distance between the trigeminal nerve root and the brainstem did not change after the stereotactic radiosurgery. It indicated that the trigeminal nerve was neurodegenerated by the radiotreatment, while the structure of brain stem was not affected. We speculated that the nerve shrinkage and sheath caused by the radiosurgery led to reduce gradually and terminate the pseudo-synaptic formed between the nerves and blood vessels to relieve the clinical symptoms in Chinese patients with primary trigeminal neuralgia. Lorenzoni et al. also found that $24 \%$ of patients had the nerve atrophy and $33 \%$ of patients had the neurological shift in MRI views after Gamma knife treatment (9). The follow-up results of the present study also showed that the pain process of trigeminal neuralgia matched with the trigeminal nerve neurotrophic process after gamma knife treatment, i.e. the pain-relief rate was $100 \%$ one-month after the treatment and the pain-relief rate remained steadily in $95 \%$ one-year after the treatment; and the incidence of facial numbness after treatment reached $75 \%$ and gradually decreased to $15 \%$ after one year.

In conclusion, the present study made clear that 1) the crosssectional area of trigeminal nerve root became smaller and MRI signals were lower in the treatment side than those in the non-treatment side after the gamma knife treatment of primary trigeminal neuralgia; 2 ) in the treatment side, the cross-sectional area of the trigeminal nerve root decreased 
Table I: The Correlation Between the Clinical Improvement and the MRI Findings

\begin{tabular}{|c|c|c|c|c|}
\hline \multicolumn{2}{|c|}{ MRI Finding } & \multirow[b]{2}{*}{ Cases } & \multicolumn{2}{|c|}{ Clinical improvement } \\
\hline $\begin{array}{l}\text { Cross-sectional area of the } \\
\text { trigeminal nerve }\left(\mathrm{mm}^{2}\right)\end{array}$ & $\begin{array}{l}\text { MRI signal } \\
\text { (Relative density) }\end{array}$ & & $\begin{array}{l}\text { Pain relief } \\
\text { (Cases) }\end{array}$ & $\begin{array}{l}\text { Facial numbness } \\
\text { (Cases) }\end{array}$ \\
\hline \multicolumn{5}{|c|}{ Before treatment } \\
\hline$<4.0$ & & 0 & & \\
\hline $4.0-4.5$ & & 0 & & \\
\hline 4.5-5.0 & & 0 & & \\
\hline $5.0-5.5$ & ++++ & 5 & $0(100.0 \%)$ & $5(100.0 \%)$ \\
\hline$>5.5$ & +++++ & 15 & $0(100.0 \%)$ & $15(100.0 \%)$ \\
\hline \multicolumn{5}{|c|}{6 months after the gamma knife treatment } \\
\hline$<4.0$ & & 0 & & \\
\hline $4.0-4.5$ & ++ & 3 & $3(100.0 \%)$ & $1(33.3 \%)$ \\
\hline $4.5-5.0$ & +++ & 3 & $2(66.7 \%)$ & $2(66.7 \%)$ \\
\hline $5.0-5.5$ & ++++ & 6 & $3(50.0 \%)$ & $4(66.7 \%)$ \\
\hline$>5.5$ & +++++ & 8 & $2(25.0 \%)$ & $8(100.0 \%)$ \\
\hline \multicolumn{5}{|c|}{12 months after the gamma knife treatment } \\
\hline$<4.0$ & + & 4 & $4(100.0 \%)$ & $0(0.0 \%)$ \\
\hline $4.0-4.5$ & ++ & 4 & $4(100.0 \%)$ & $0(0.0 \%)$ \\
\hline $4.5-5.0$ & +++ & 5 & $5(100.0 \%)$ & $0(0.0 \%)$ \\
\hline $5.0-5.5$ & ++++ & 4 & $4(100.0 \%)$ & $1(25.0 \%)$ \\
\hline$>5.5$ & +++++ & 3 & $2(66.7 \%)$ & $2(66.7 \%)$ \\
\hline \multicolumn{5}{|c|}{24 months after the gamma knife treatment } \\
\hline$<4.0$ & + & 3 & $3(100.0 \%)$ & $0(0.0 \%)$ \\
\hline $4.0-4.5$ & ++ & 5 & $5(100.0 \%)$ & $0(0.0 \%)$ \\
\hline $4.5-5.0$ & +++ & 6 & $5(83.3 \%)$ & $1(16.7 \%)$ \\
\hline $5.0-5.5$ & ++++ & 4 & $3(75.0 \%)$ & $2(50.0 \%)$ \\
\hline$>5.5$ & +++++ & 2 & $1(50.0 \%)$ & $2(100.0 \%)$ \\
\hline \multicolumn{5}{|c|}{36 months after the gamma knife treatment } \\
\hline$<4.0$ & + & 3 & $3(100.0 \%)$ & $0(0.0 \%)$ \\
\hline $4.0-4.5$ & ++ & 5 & $5(100.0 \%)$ & $1(20.0 \%)$ \\
\hline 4.5-5.0 & +++ & 7 & $6(85.7 \%)$ & $3(42.9 \%)$ \\
\hline $5.0-5.5$ & ++++ & 4 & $1(25.0 \%)$ & $3(75.0 \%)$ \\
\hline$>5.5$ & +++++ & 1 & $0(0.0 \%)$ & $1(100.0 \%)$ \\
\hline
\end{tabular}

significantly after the gamma knife treatment; 3) the straight distance between the trigeminal nerve root and the brainstem did not change after the gamma knife treatment; and 4) there was good correlation between the clinical improvement and the MRI findings. The data suggested that the pain-relief induced the stereotactic radiosurgery might be related with the atrophy of the trigeminal nerve root in Chinese patients with primary trigeminal neuralgia.

\section{REFERENCES}

1. Babu R, Murali R: Arachnoid cyst of the cerebellopontine angle manifesting as contralateral trigeminal neuralgia: Case report. Neurosurg 28:886-887, 1991
2. Bayer DB, Stenger TG: Trigeminal neuralgia: An overview. Oral Surg Oral Med Oral Pathol 48:393-399, 1979

3. Burchiel KJ: A new classification for facial pain. Neurosurg 53:1164-1167, 2003

4. Dhople A, Kwok Y, Chin L, Shepard D, Slawson R, Amin P, Regine W: Efficacy and quality of life outcomes in patients with atypical trigeminal neuralgia treated with gamma knife radiosurgery. Int J Radiat Oncol Biol Phys 69:397-403, 2007

5. Dhople AA, Adams JR, Maggio WW, Naqvi SA, Regine WF, Kwok Y: Long-term outcomes of Gamma Knife radiosurgery for classic trigeminal neuralgia: Implications of treatment and critical review of the literature. Clinical article. J Neurosurg 111:351-358, 2009 
6. Dvorak T, Finn A, Price LL, Mignano JE, Fitzek MM, Wu JK, Yao KC: Retreatment of trigeminal neuralgia with Gamma Knife radiosurgery: Is there an appropriate cumulative dose? Clinical article. J Neurosurg 111:359-364, 2009

7. Guo S, Chao ST, Reuther AM, Barnett GH, Suh JH: Review of the treatment of trigeminal neuralgia with gamma knife radirosurgery. Stereotact Funct Neurosurg 86:135-146, 2008

8. Jennetta PJ: Arteaial compression of the trigeminal nerve at the pons in patients with trigeminal neuralgia. Neurosurg 26:159-162, 1987

9. Lorenzoni JG, Massager N, David P, Devriendt D, Desmedt F, Brotchi J, Levivier M: Neurovascular compression anatomy and pain outcome in patients with classic trigeminal neuralgia treated by radiosurgery. Neurosurg 62:368-375, 2008

10. Park SH, Hwang SK, Kang DH, Park J, Hwang JH, Sung JK: The retrogasserian zone versus dorsal root entry zone: comparison of two targeting techniques of gamma knife radiosurgery for trigeminal neuralgia. Acta Neurochir (Wien) 152:1165-1170, 2010
11. Park YS, Kim JP, Chang WS, Kim HY, Park YG, Chang JW: Gamma knife radiosurgery for idiopathic trigeminal neuralgia as primary vs. secondary treatment option. Clin Neurol Neurosurg 113:447-452, 2011

12. Prasad S, Galetta S: Trigeminal neuralgia historical notes and current concept. Neurologist 15:87-94, 2009

13. Sindou M, Keravel Y: Algorithms for neurosurgical treatment of trigeminal neuralgia. Neuro-Chirurgie 55:223-225, 2009

14. Sindou M, Tatli M: Treatment of trigeminal neuralgia with thermorhizotomy. Neuro-Chirurgi 55:203-210, 2009

15. Zakrzewska JM, Akram H: Neurosurgical interventions for the treatment of classical trigeminal neuralgia. Cochrane Database of Systematic Reviews (Online) 9:CD007312, 2011

16. Zhao ZF, Yang LZ, Jiang CL, Zheng YR, Zhang JW: Gamma Knife irradiation-induced histopathological changes in the trigeminal nerves of rhesus monkeys. J Neurosurg 113:39-44, 2010

17. Zheng LG, Xu DS, Kang CS, Zhang ZY, Li YH, Zhang YP, Liu $D$, Jia Q: Stereotactic radiosurgery for primary trigeminal neuralgia using the Leksell Gamma unit. Stereotact Funct Neurosurg 76:29-35, 2001 